\title{
Bladder tumours and occupation: a coroner's notification scheme
}

\author{
C. A. VEYS
}

The North Staffordshire Medical Institute Research Unit, Hartshill, Stoke-on-Trent, ST4 7NY

\begin{abstract}
Veys, C. A. (1974). British Journal of Industrial Medicine, 31, 65-71. Bladder tumours and occupation: a coroner's notification scheme. The disease of bladder cancer accounted for 2763 male and 1107 female deaths in England and Wales during 1971. How much of this total is influenced by aetiological factors in the working environment is still largely unknown and is only now beginning to be studied.

In order to elucidate this question further, a coroner's notification scheme for all bladder tumours occurring within a defined geographical area was started in 1965. Details of all persons dying, on whose death certificate a bladder tumour was mentioned, were notified to the coroner's office within a six-year period (1965-70). A necropsy was carried out in almost all cases. A subsequent searching enquiry into the lifetime occupational history was conducted and this was then related to two industrial check-lists previously drawn up, on which the occupations listed exhibited either a true cause and effect relationship, or were merely associated in statistical terms.

The finding that about $20 \%$ of persons dying of this disease had a suspicious occupational history of exposure to a carcinogen was broadly in agreement with some other recent surveys whose methodology was different. In only one third of these cases, however, could the working environment be directly and realistically implicated.

The study supports the conclusion that the importance of occupational factors in the aetiology of bladder tumours has hitherto been underestimated.
\end{abstract}

Bladder cancer accounted for 2131 male and 917 female deaths in England and Wales during 1960. By 1970, deaths from this disease had risen to 2689 for men and 1139 for women, a total increase of 780 within the decennium. The crude death rate for bladder cancer per million of the population was 67 in 1960, climbing gradually to 78 in 1970; the rise was steeper for men (96-113) than for women (39-45) during the same period. In 1971 there were 2763 male deaths attributed to bladder cancer, but only 1107 for women-less than the previous year in fact. The current mortality ratio male : female is thus $2 \cdot 4: 1$. The tumour is placed seventh in order of numerical magnitude for male deaths due to malignant disease, whereas the corresponding position in female cancer deaths is eleventh.
A comparative study of cancer registration rates for England and Wales (International Union Against Cancer, 1970) also reflects the small but definite rise in the incidence of bladder cancer during this last decade. The increase in morbidity appears to be confined specifically to age groups over 55 years:

It is difficult to accord a satisfactory and full explanation for the rise. Certainly mortality from this form of cancer is generally slightly higher in urban than in rural areas, presumably because the town dweller is more exposed to potentially dangerous carcinogenic compounds, and because there have been specific risks in certain occupations.

The role of smoking as a probable factor in the aetiology of bladder cancer is becoming increasingly documented (Royal College of Physicians, 1971; 
Cole, Monson, Haning, and Friedell, 1971), and it has been shown that cigarette smoke contains $2 \times 10^{-2} \mu \mathrm{g}$ of beta naphthylamine per cigarette (equivalent to $1 \mu \mathrm{g} / 50$ cigarettes).

It has, therefore, been tentatively suggested that this increasing prevalence may in part reflect a delayed enhancement from smoking, as well as the operation of occupational and environmental influences. The latent period inherent in both lung and bladder cancer is usually a long one; it is probably different for each type of tumour, so that any delayed carcinogenic effects resulting from the same cause are not necessarily apparent within the same time span.

Cohort analysis of the situation does not at first sight accord with the suggestion that smoking is the predominant factor accounting for the rise. For both males and females the rise from cohort to cohort for bladder cancer mortality has not yet ceased, and the age-specific rise is confined to those over 60 years of age. This can be contrasted with the lung cancer picture, in which the rise from cohort to cohort in males has now slackened or ceased, whereas that for females is accelerating. Therefore, if the increase really relates to the smoking hypothesis, one would expect the type of cohort pattern found for bladder cancer to be more compatible with that found for lung cancer in both sexes. It is, of course, the survivor population, i.e., those who have not died of lung cancer, who subsequently might succumb to a bladder tumour, especially if the inherent latent period before development of bladder cancer is the longer one, as is probably the case. The rising agespecific prevalence and death rates (over 55 years and 60 years respectively) would accord with this fact.

All one can say is that the current situation is the result of a complex interaction of many factors not yet clearly defined.

The aetiological factors already thought to be implicated in the causation of urinary tract cancer in man have recently been reviewed by Clayson and Cooper (1972). In brief they are-smoking, occupational exposure to certain aromatic amines, an excessive consumption of analgesics such as phenacetin, in the past (for an unfortunate few) drug treatment for polycythaemia vera with chlornaphazin (a 2-naphthylamine mustard), and urinary schistosomiasis.

Dietary factors may also be implicated: in cows, for example, a bracken toxin, probably an unsaturated lactone which may pass into the milk, causes haematuria and bladder tumours. Excessive coffee drinking has also been postulated as a possible causative agent, but the evidence for this is not well substantiated nor is it supported by animal experimental work. Abnormal tryptophan metabolism has also been put forward as a factor in promoting bladder neoplasia, but again concrete evidence for the participation of these endogenous metabolites in bladder carcinogensis is considered to be weak.

Compounds of the aromatic amine class which are labelled as urinary carcinogens are-benzidine, alpha- and beta-naphthylamine, 4-aminodiphenyl, and 4-nitrodiphenyl, together with some of their derivatives and salts. Other aromatic amine chromogens which may be used on the laboratory bench are suspected human bladder carcinogens, e.g., o-tolidine, and o-dianisidine.

A recent regional study of the incidence of cancer of the bladder shows that the disease is more prevalent in the south-east of England than elsewhere in both sexes (Office of Population Censuses and Surveys, 1972). Although an occupational exposure to the known aromatic amine carcinogens has been implicated as an important aetiological factor, it cannot be the only one, because the observed area pattern of incidence is much the same for both sexes. The study also revealed that the distribution pattern of bladder cancer somewhat resembled that for lung cancer. However, since the definition of malignancy in bladder tumours is often unprecise, it was concluded that some of the area differences in the prevalence of bladder cancer may in fact be due primarily to this variation in diagnostic criteria.

How much bladder cancer is occupationally induced? It has been generally held that only about $1 \%$ of all bladder cancer in industria'ized societies had an occupational aetiology. This is probably an underestimate, and it has never been substantiated by published data. However, more recent surveys on patients who were interviewed in depth about their working history suggest that perhaps nearer $20 \%$ of bladder cancer in industrial communities may be linked with occupational factors, and that some occupations which were not previously suspected may also be subject to this hazard (Anthony and Thomas, 1970; Cole et al., 1971). It is not yet possible to determine whether these newly suspect industries have used any of the recognized aromatic amine human bladder carcinogens or whether other quite different agents are involved. There is a need, therefore, for further investigations to establish more precisely the extent of the occupational factors, if any, which might be implicated.

Reviews of those occupational groups which are likely to be implicated in a cause and effect relationship with bladder cancer have been made by Case (1966) and recently by Clayson and Cooper (1970, 1972).

The 'Lucy' Inquest (Lancet, 1965a) on a former cable-worker dying of bladder cancer of occupational origin aroused public and parliamentary concern in England. After another similar inquest in Bath in September 1965 (Lancet, 1965b) much discussion 
ensued about the provision of adequate screening facilities for early diagnosis in previously exposed workmen, as well as on the need to set up detailed epidemiological studies to look further into the whole problem.

Two coroners (Hails, 1965; Thurston, 1965) on their own initiative offered to help in the research. A doctor certifying death is required to report the death to the coroner in certain defined circumstances. One of these is when there are grounds for supposing that death might have been directly due to, or in part contributed by, any employment followed by the deceased during his lifetime. It is only a further small step to elect to make certain diseases locally notifiable on a voluntary basis in order to permit the relevant enquiry; this has always been an established principle of good preventive medicine and public health.

In North Staffordshire, the small but continuing rise in the prevalence of bladder tumours has been recorded and studied. The figure, for example, shows the situation as it has occurred there quinquennially since 1945 . The data depicted are derived from a very detailed analysis of all death certificates relating to the area, from hospital records, and from the returns to a local cancer registration scheme which has been operating since that time.

The details of 1310 cases of bladder tumour thus derived from the mortality and morbidity records were recorded onto cards and assessed numerically (Figure).

These data were also used to construct quinquennial age-specific incidence rates for bladder tumours for the county borough of Stoke-on-Trent situated within North Staffordshire. A study of the rates shows that the rise is indeed a real one over time; that it is predominant in age groups over 55 years; and that it is unlikely to be due to better diagnostic criteria or to the appointment of a fulltime consultant urologist to the area in 1965. Whereas 11 new cases were registered in the county borough in 1946, some 34 were registered in 1970; this is a threefold increase, not matched by a corresponding augmentation in the population being served.

North Staffordshire, situated in central England, has a population of approximately half a million people; its industry is varied but concentrated, and because the region is relatively segregated geographically, it is conveniently served by a single hospital centre. Local industries include iron and steel, foundries, chemicals, printing, colours and dyes, rubber and cable making, engineering, paper, coalmining, ceramics, refractory and pottery manufacture. This convenient 'epidemiological island' midway between the conurbation of Manchester to the north and Birmingham to the south greatly facilitated the study described here.

\section{Material and method}

A voluntary area notification scheme for all bladder tumours was started in 1965 and has continued in operation since that time. It includes all tumours that were mentioned on death certificates and registered within the county borough of Stoke-on-Trent which has a population of approximately 265000 .

Within the six-year period (1965-70), every death certificate for county borough residents, on which a bladder tumour was recorded, was notified to the City Coroner's Office. The county borough boundary line was strictly adhered to for residency qualification. In almost every case a necropsy was carried out to confirm the diagnosis. Histological material was taken for examination in all cases in which the occupational history was thought to be relevant, and for most of the others.

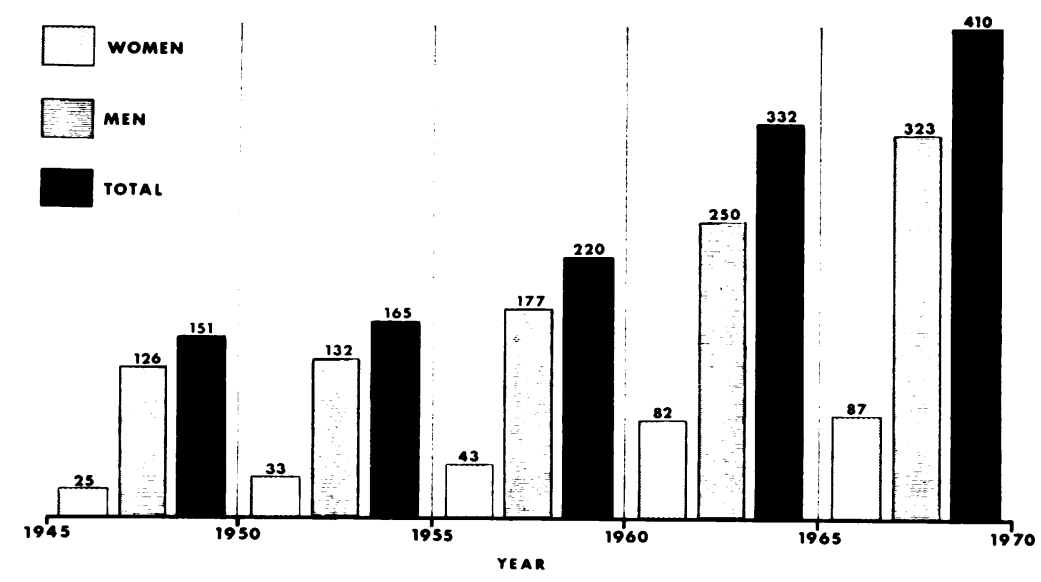

FIGURE Prevalence of bladder tumours in North Staffordshire (1945-70). 
For each decedent a full and detailed occupational history was taken by the coroner's officer from the nearest relative, and this was supplemented by other records, either from industry or from any other source made available to the coroner subsequent to his further enquiry.

All general practitioners, hospital clinicians, and pathologists had agreed to co-operate. Finally, a check was made against the death certificate returns made to the local Registrar, in order to ensure that no cases had inadvertently been missed.

The occupational histories were then related to two industrial checklists (A and B), which had previously been drawn up. Checklist A (Table 1) lists eight occupational groups in which an excess tumour association can be linked with causative factors in certain circumstances of employment. Checklist B (Table 2) is composed of a further six groups in which a statistical association only has so far been postulated. Three additional groups in checklist B, namely coalmining, electrical workers, cooks, and kitchen workers, exhibit only a rather tenuous association, and they have therefore not been used in this study in the compilation of the results; they are listed for the sake of completeness.

Any one piece of statistical evidence implying association may be discounted on the grounds that statistical coincidence alone does not necessarily imply a causative relationship. This is a reasonable argument, but it must begin to lose some of its validity as more and more coincidences are uncovered, and as a biologically plausible explanation evolves. The six occupational groups in

\section{TABLE 1}

Bladder Tumours and OCCUPATION INDUSTRIAL CHECKLIST A

An association/causation linkage established

Chemical and dyestuffs manufacture

(Adelstein, 1972: Anthony and Thomas, 1970: Case,

1966; Case et al., 1954; Goldblatt, 1949; HM Chief

Inspector of Factories, 1965; Melick et al., 1955; Wynder,

Onderdonk, and Mantel, 1963; Scott, 1952).

Pigment and paint manufacture

(Case and Pearson, 1954; HM Chief Inspector of Factories, 1965; Ministry of Labour, 1966).

Rubber and cable-making

(Adelstein, 1972; Case, 1966; Case and Hosker, 1954; Davies, 1965; Guira, 1971; HM Chief Inspector of Factories, 1965; Lockwood, 1961; Veys, 1969).

Textile-dyeing and printing

(Anthony and Thomas, 1970; Case, 1966; HM Chief Inspector of Factories, 1965; Lockwood, 1961; Wynder et al., 1963).

Gas industry

(Adelstein, 1972; Battye, 1966; Bruusgard, 1959; Case, 1966; Doll et al., 1965 and 1972; Henry et al., 1931; HM Chief Inspector of Factories, 1965).

Laboratory workers

(Anthony and Thomas, 1970; Case, 1966; Chester Beatty Research Institute, 1966; HM Chief Inspector of Factories, 1965).

Rodent controllers

(Case, 1966; HM Chief Inspector of Factories, 1965).

Patent fuel, tar, and pitch workers

(Battye, 1966; Case, 1966; Henry et al., 1931).
TABLE 2

BLADDER TUMOURS AND OCCUPATION INDUSTRIAL CHECKLIST B

Only statistical association recorded

Workers with leather

(Henry et al., 1931; Lockwood, 1961; Wynder et al., 1963; Cole et al., 1972).

Stokers (especially furnacemen)

(Adelstein, 1972; HM Chief Inspector of Factories, 1965; Wynder et al., 1963).

Hairdressers

(Anthony and Thomas, 1970; Dunham et al., 1968; Wynder et al., 1963).

Tailoring

(Anthony and Thomas, 1970; Lockwood, 1961 ; Wynder et al., 1963).

Printing

(Henry et al., 1931 ; HM Chief Inspector of Factories, 1965; Ministry of Labour, 1966).

Engineering (with metals)

(Anthony and Thomas, 1970; Dunham et al., 1968; Wynder et al., 1963).

Coalmining

(Staszewski, 1966; Wynder et al., 1963).

Electrical workers

(Anthony and Thomas, 1970).

Cooks and kitchen workers

(Cole et al., 1972).

checklist B, therefore, still only accord with the former discountable category, whereas those in checklist $\mathbf{A}$ have satisfied at least some of the criteria which more strongly favour an association/causation relationship (Bradford Hill, 1966).

Both checklists A and B were drawn up from the available published literature, the relevant references being given under their appropriate occupational groups.

\section{Results}

\section{Male notifications}

A total of 144 death certificates mentioned a bladder tumour and were notified under the scheme during the six-year period (1965-70). Some 39 names relating to men who were resident outside the administrative boundary line of the county borough were discounted, leaving 105 cases for subsequent analysis. Thirty-six (34\%) of these had worked in occupations identifiable in both checklists, i.e., 19 $(18 \%)$ with checklist $A$ and $17(16 \%)$ with checklist B (Table 3). The remainder (69 cases) showed no relevant occupational history.

During the same six-year period, one might have expected 89 cases to have been notified had national certification rates, suitably adjusted for age and for the urban factor, been operating. National certification rates for bladder tumours (Chester Beatty Research Institute, 1968) record the number of death certificates on which a benign or malignant tumour is mentioned as the cause of death on the certificate under the heading I or II, i.e., whether death is 


\section{TABLE 3}

\section{HM CORONER's Notification SCHEME FOR BLADDER TUMOURS (1965-70)}

MALE NOTIFICATIONS-105. A total of $36(34 \%)$ gave a suspicious occupational history according to the two checklists used.

Checklist A

3 colour workers

11 rubber workers

1 cable worker

1 gas worker

1 rodent controller

2 tar workers

Total $\overline{19}(18 \%)$

Checklist B

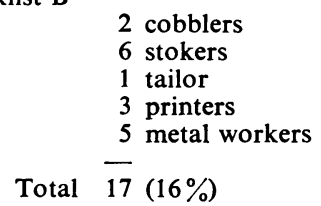

FEMALE NOTIFICATIONS-25. Only $3(12 \%)$ gave a suspicious occupational history according to checklist A. Checklist A Checklist B

$$
\begin{array}{lll} 
& \begin{array}{l}
1 \\
1 \\
\text { Total }
\end{array} \\
1 & \text { rubber worker } \\
\text { nurse } & (12 \%)
\end{array}
$$

Nil actually assigned to this cause or not. Thus the certification rate is, as a result, always a little higher than the death rate for this disease.

Within $95 \%$ confidence limits, one might have expected as few as 70 or as many as 108 such certificates to have been notified in the county borough in question during the six years. Thus the number of cases actually notified (106) is not in statistical terms significantly in excess of expectation; it is in the high normal range.

\section{Female notifications}

A total of 38 cases of bladder tumour in females recorded on death certificates were notified within the six-year period of the scheme. However, 13 women lived outside the administrative boundaries of the county borough, so these were not relevant to the subsequent analysis. Of the 25 cases relevant, $3(12 \%)$ had worked in environments for which an occupational factor might have been implicated, according to checklist A only (Table 3 ). The remainder (22 women) showed no suspicious occupational history whatsoever in the whole of their working or domestic life.

During the same period of time one might have expected 39 cases to have been notified had national certification rates, suitably adjusted for age and for the urban factor, been operating. Within $95 \%$ confidence limits, as few as $\mathbf{1 8}$ or as many as $\mathbf{4 0}$ notifications could have been made without these totals being considered as outside normal limits. The number of cases actually notified (25), therefore, is less than expected (29) but not significantly so statistically.

\section{Discussion}

It should not be inferred from these results that as many as $18 \%$ of the deaths due to, or associated with, bladder tumour can be directly linked to an occupational aetiology (Table 3). The results do suggest, however, that perhaps one in five of persons dying from this disease may possibly have a related occupational history. Their work history at least would have merited some further enquiry.

For such enquiry it is important to probe into the life-long occupational history. Some of the individuals listed under one main occupation in this study had also worked in other jobs which were relevant. For example, among the 11 rubber workers recorded under checklist $A$ in Table 3, three had also been stokers; two had been metal workers; and there had also been one hairdresser and one cableworker among them. The rodent control operator had also been a tar worker. Among the six stokers (checklist B, Table 3) one had been a chemical worker and two had been life-long blacksmiths.

These are inherent difficulties in indicting without reservation even those occupations known to have a strong association with bladder cancer. For example, in the area in which this study was conducted an appreciable number of rubber and cable workers reside. There is also widespread coal mining, and in particular a very large concentration of the pottery industry. Inevitably, therefore, chance alone will dictate many of these as common employments, for a large proportion of the population will have worked in one or all of these major representative industries within the district. Ascription of tumours to occupations, therefore, requires a most careful and critical evaluation.

It was possible, however, because of the nature of the coroner's enquiry before and at the inquest, to probe in great detail into those occupational factors thought to be relevant. For example, in only two of the 11 rubber workers listed in Table 3 under checklist A were there reasonable grounds for concluding that occupation played a full part in aetiology. The two men were exposed to an antioxidant known to have contained traces of the recognized human bladder carcinogen, beta-naphthylamine, in use in the industry prior to 1950 ; the other nine were not.

Altogether, it was concluded that six men, 
namely one-third of the total listed under checklist A, and one of the three women had bladder tumours which could be directly attributed to the occupational or environmental factors operating. Thus, while it is one thing to list suspicious occupational groupings, it is quite another to indict them in a specific sense.

Although bladder cancer is still a killing disease, not all patients who suffer from it eventually die of it. For example, in the course of the study it became apparent, by cross-checking with the records of the local Cancer Registration Scheme, that a further 20 men (i.e., almost $20 \%$ of the total notifications) who suffered from a bladder tumour and had died within the same six-year period, did not have the disease mentioned on their death certificate. These cases, therefore, were not notified under the scheme; likewise there were six other cases of bladder tumour in women who died, but who did not have the tumour mentioned on their death certificate.

There are few studies in the recorded literature which attempt to define the significance of occupational factors in women. However, taking due account of the usual sex ratio operating in this disease, as well as of the obvious fact that much fewer women have worked in the related occupations, it is apparent that the prevalence of both the occupational and the so-called 'naturally occurring tumours' is much reduced. Special factors may be operating which inherently protect the female.

Some recent morbidity surveys (Anthony and Thomas, 1970; Cole, Hoover, and Friedell, 1972) have matched the occupational histories of patients with bladder tumour with those of control patients not suffering from the disease. This present study has in contrast sought out retrospective information using mortality data only. There is nevertheless a surprising measure of agreement between these two different approaches in that the occupational history is possibly linked with aetiology in about $20 \%$ of the cases investigated.

It was not possible in this study to compare the bladder cancer deaths with a control series of deaths in circumstances not suggesting an occupational cause. The study was designed to quantify the known or suspect occupation and then critically to appraise these individually.

Because the scheme encompassed the notification of all cases of bladder tumour, one further occupational group can now be added to checklist A. It is that of firelighter-making as it used to be conducted locally. The case exemplifies how detailed were the subsequent investigations and coroner's enquiries in those instances where a possible occupational influence was suspected. Under the scheme the death of a young man (aged 40 years) from bladder cancer was notified. It transpired that his tumour was diagnosed some 14 years previously, when he was only 26 years old. Eleven years prior to his first symptom of haematuria he worked for two years making firelighters. This work entailed heating a mixture of naphtha salt and creosote oil in a cauldron and then dipping wooden shavings into the mix before compressing these into bundles of firelighters.

Samples of the creosote oil and naphtha salt were unexpectedly available for analysis. The former was found to contain about $25 \mathrm{ppm}$ of beta naphthylamine and about $6 \mathrm{ppm}$ of the alpha isomer. Only about $2 \mathrm{ppm}$ of beta naphthylamine was detected in the naphtha salt. In both samples a number of unidentified heterocyclic amines were also detected. These are small quantities of known aromatic amine carcinogens, but the prolonged and close contact that the firelighter-maker would have had with fumes emanating from the boiling mixture on the work bench, as he continuously leant over it, would ensure a high personal exposure.

The exposure was likely to have been greater than that which apparently more than doubles the expected mortality rate from bladder cancer in gas workers, even though the atmospheric quantities measured in the retort house were probably underestimated (Battye, 1966; Doll et al., 1972). A uroepithelial carcinoma is rare in the population of the region ( 1 case per 200000 ) in the relevant age group. This was the second such case to have come to light under the scheme; the other occurred in a woman who ran her own firelighter business for 25 years. Although both 1- and 2-naphthylamine are detectable in the chemicals being handled, they are not necessarily the only ones present in fumes from coal tar derivatives that are capable of causing cancer of the bladder.

Differences between surveys must reflect the fact that some industries are not represented in all the localities investigated. Because the area in which this coroner's notification scheme was conducted is not apparently exceptional, as far as its expected mortality from bladder cancer is concerned, one might reasonably conclude that the situation is representative of that in many other urban areas. If this is indeed the case, it would appear that the part occupational factors play in the aetiology of this disease may hitherto have been somewhat underestimated.

I would like to thank Mr. F. G. Hails for his invitation to join the Coroner's Notification Scheme in order to advise him on its medical and epidemiological aspects.

\section{References}

Adelstein, A. M. (1972), Occupational mortality: cancer. Annals of Occupational Hygiene, 15, 53-57.

Anthony, Honor M. and Thomas, Gretta M. (1970). Tumours of the urinary bladder: an analysis of the occupations of 1,030 patients in Leeds, England. Journal of the National Cancer Institute, 45, 879-895. 
Battye, R. (1966). Bladder carcinogens occurring during the production of 'town gas' by coal carbonization. Transscript of XV International Conference on Industrial Medicine, Vienna July 1966, p. 153-158, Vol. 3 Hygiene, Toxicology, Occupational Diseases.

Bradford Hill, A. (1966). Statistical evidence and inference. Principles of Medical Statistics, 8th ed., Chapter 24, pp. 302-314. The Lancet, London.

Bruusgaard, A. (1959). Opptreden av visse kreftformer blant gassverkarbeidere. Tidsskrift for der Norske Loegeforening, 79, 755-756.

Case, R. A. M. (1966). Tumours of the urinary tract as an occupational disease in several industries. Annals of the Royal College of Surgeons of England, 39, 213-235.

- , and Hosker, Margery E. (1954). Tumour of the urinary bladder as an occupational disease in the rubber industry in England and Wales. British Journal of Preventive and Social Medicine, 8, 39-50.

- Hosker, M. E., McDonald, D. B., and Pearson, J. T. (1954). Tumours of the urinary bladder in workmen engaged in the manufacture and use of certain dyestuff intermediates in the British chemical industry. Part I. British Journal of Industrial Medicine, 11, 75-104.

- , and Pearson, J. T. (1954). Part II. Further consideration of the role of aniline and of the manufacture of auramine and magenta (fuchsine) as possible causative agents. British Journal of Industrial Medicine, 11, 213-216.

Chester Beatty Research Institute (1966). Precautions for Laboratory Workers who handle Carcinogenic Aromatic Amines. Institute of Cancer Research, Royal Cancer Hospital, London.

(1968). Death Rates for 1956-1960 and 1961-1965 by R. A. M. Case, C. Coghill and J. L. Harley. (Supplement to Cancer Death-Rates by Site, Age and Sex, England and Wales, 1911-1953, 1954 and 1955 by R. A. M. Case and J. T. Pearson). Institute of Cancer Research, Royal Cancer Hospital, London.

Clayson, D. B. and Cooper, E. H. (1970). Cancer of the urinary tract. In Advances in Cancer Research, Vol. 13, pp. 271-381. Academic Press, London.

(1972). Recent progress in bladder cancer. European Journal of Cancer, 8, 221-223.

Cole, P., Hoover, R., and Friedell, G. H. (1972). Occupation and cancer of the lower urinary tract. Cancer, 29, 12501260.

_ Monson, R. R., Haning, H., and Friedell, G. H. (1971). Smoking and cancer of the lower urinary tract. New England Journal of Medicine, 284, 129-134.

Davies, Joan M. (1965). Bladder tumours in the electric-cable industry. Lancet, 2, 143-146.

Doll, R., Fisher, R. E. W., Gammon, E. J., Gunn, W., Hughes, G. O., Tyrer, F. H., and Wilson, W. (1965). Mortality of gas workers with special reference to cancers of the lung and bladder, chronic bronchitis and pneumoconiosis. British Journal of Industrial Medicine, 22, 1-12. , Vessey, M. P., Beasley, R. W. R., Buckley, A. R., Fear, E. C., Fisher, R. E. W., Gammon, E. J., Gunn, W., Hughes, G. O., Lee, K., and Norman-Smith, Beatrice (1972). Mortality of gasworkers-final report of a prospective study. British Journal of Industrial Medicine, 29, 394-406.
Dunham, L. J., Rabson, A. S., Stewart, H. L., Frank, A. S., and Young, J. L. (1968). Rates, interview and pathology study of cancer of the urinary bladder in New Orleans, Louisiana. Journal of the National Cancer Institute, 41, 683-709.

Goldblatt, M. W. (1949). Vesical tumours induced by chemical compounds. British Journal of Industrial Medicine, 6, 65-81.

Guira, A. C. (1971). Bladder carcinoma in rubber workers. Journal of Urology (Baltimore), 106, 548-552.

Hails, F. G. (1965). Bladder tumours in industry. Lancet, 2, 587 (correspondence).

Henry, S. A., Kennaway, N. M., and Kennaway, E. L. (1931). The incidence of cancer of the bladder and prostate in certain occupations. Journal of Hygiene, 31, 125-137.

HM Chief Inspector of Factories (1965). Annual Report on Industrial Health. Cmnd. 3081, p. 57. HMSO, London.

International Union against Cancer (1970). Cancer Incidence in Five Continents, Vol. II. Edited by R. Doll, C. S. Muir, and J. A. H. Waterhouse. UICC, Geneva. SpringerVerlag, Berlin (Vol. I published in 1966).

Lancet (1965a). Leading article: Occupational bladder tumours and the control of carcinogens. 1, 306-307. Report of an Inquest, p. 328.

(1965b). Leading article: Bladder tumours in industry. 2, 627-628. Report on an Inquest, p. 635.

Lockwood, K. (1961). On the aetiology of bladder tumours in Kobenhavn-Frederiksberg-an inquiry of 369 patients and controls. Acta Pathologica et Microbiologica Scandinavia, Supplementum 145, p. 48.

Melick, W. F., Escue, H. M., Naryka, J. J., Mezera, R. A., and Wheeler, E.P.(1955). The first reported cases of human bladder tumors due to a new carcinogen-zenylamine. Journal of Urology, 74, 760-766.

Minıstry of Labour (1966). F.2205, Notice to Workers and Former Workers in the Chemical Dyestuffs, Textile Dyeing, Printing and Paint Manufacturing Industries. HMSO, London.

Office of Population Censuses and Surveys (1972). Cancer Studies on Medical and Population Subjects No. 24. Incidence in Great Britain (1963-66). HMSO, London.

Royal College of Physicians (1971). Smoking and Health Now, pp. 96-97. Pitman, London.

Scott, T. S. (1952). The incidence of bladder tumours in a dyestuffs factory. British Journal of Industrial Medicine, 9, 127-132.

Staszewski, J. (1966). Smoking and cancer of the urinary bladder in males in Poland. British Journal of Cancer, 20, 32-35.

Thurston, G. B. (1965). Bladder tumors in industry. Lancet, 2, 695 (correspondence).

Veys, C. A. (1969). Two epidemiological inquiries into the incidence of bladder tumors in industrial workers. Journal of the National Cancer Institute, 43, 219-226.

Wynder, E. L., Onderdonk, J., and Mantel, N. (1963). An epidemiological investigation of cancer of the bladder. Cancer (Philadelphia), 16, 1388-1407.

Received for publication January 22, 1973.

Accepted for publication May 4, 1973. 